\title{
Utilização de glyphosate associado a herbicidas aplicados em pós-emergência na cultura da soja geneticamente modificada ${ }^{1}$
}

\author{
Use of glyphosate associate to herbicides applied in post-emergence on soybean \\ crop genetically modified
}
Joaquim J. de Almeida Júnior ${ }^{2 *}$, Alberto Leão de Lemos Barroso², Alessandro Guerra da Silva ${ }^{2}$, Sérgio de Oliveira Procópio ${ }^{3}$

Resumo - A frequente utilização de associações entre herbicidas pós-emergentes, tem deixado inúmeras indagações a respeito da seletividade e eficácia para o controle de plantas daninhas na cultura da soja. Assim, este trabalho teve por objetivo avaliar a seletividade e a eficácia de misturas em tanque de herbicidas, no manejo de plantas daninhas na cultura da soja Roundup Ready $^{\circledR}$. Para esta finalidade, foram avaliados os tratamentos: glyphosate $\left(960 \mathrm{~g} \mathrm{ha}^{-1}\right)$, glyphosate+adjuvante Agrus $200^{\circledR}\left(960+200 \mathrm{~g} \mathrm{ha}^{-1}\right)$, glyphosate+chlorimuron-ethyl $(960+12,5 \mathrm{~g}$ $\left.\mathrm{ha}^{-1}\right)$, glyphosate+lactofen $\left(960+96 \mathrm{~g} \mathrm{ha}^{-1}\right)$ e testemunhas capinada e sem capina. A aplicação dos tratamentos em pós-emergência ocorreu quando a soja cultivar CD $219 \mathrm{RR}^{\circledR}$ encontrava-se no estádio fenológico V4 (terceira folha trifoliolada). Os níveis de controle das espécies Alternanthera tenella, Senna obtusifolia, Cenchrus echinatus e Commelina benghalensis e os sintomas de fitointoxicação da cultura foram avaliados aos 3, 7, 14 e 21 dias após a aplicação. A associação entre glyphosate+lactofen proporcionaram os maiores níveis de fitotoxidade sobre a cultura. Todos os tratamentos herbicidas foram eficientes no controle Alternanthera tenella e Cenchrus echinatus, no entanto apresentaram controle insatisfatório da Senna obtusifolia e Commelina benghalensis, causando reduções significativas na produtividade da cultura.

Palavras chaves: Mistura em tanque, soja Roundup Ready ${ }^{\circledR}$, glyphosate, Glycine max.

\begin{abstract}
Frequent utilization of associations among post-emergence herbicides has remained a lot of questions about the selectivity and effectiveness of weeds control in soybean crop. Thus, this study aimed to evaluate the selectivity and effectiveness of herbicides tank mixtures on weed management in Roundup Ready ${ }^{\circledR}$ soybean crop. For this purpose, the following treatments were evaluated: glyphosate $\left(960 \mathrm{~g} \mathrm{ha}^{-1}\right)$, glyphosate + Agrus $200^{\circledR}$ adjuvant $\left(960+200 \mathrm{~g} \mathrm{ha}^{-1}\right)$, glyphosate+chlorimuron-ethyl $\left(960+12.5 \mathrm{~g} \mathrm{ha}^{-1}\right)$, glyphosate+lactofen $\left(960+96 \mathrm{~g} \mathrm{ha}^{-1}\right)$ and checks with and without weeds. The spraying of treatments in post emergence conditions occurred when CD $219 \mathrm{RR}^{\circledR}$ soybean genotype plants achieved V4 leaf stage (third leaf stage). Control levels of Alternanthera tenella, Senna obtusifolia, Cenchrus echinatus and Commelina benghalensis species and crop phytotoxicity symptoms were evaluated at 3, 7, 14 and 21 days after application. The association between glyphosate+lactofen provided higher levels of

\footnotetext{
* Autor para correspondência

${ }^{1}$ Recebido para publicação em 26/12/2010 e aceito10/02/2011.

${ }^{2}$ Docentes da Faculdade de Agronomia da Fesurv - Universidade de Rio Verde, Rio Verde-GO, Brasil, all_barroso@hotmail.com

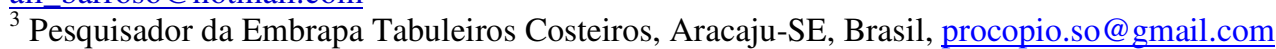

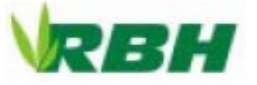


phytotoxicity over the crop. All herbicide treatments evaluated were efficient in controlling Alternanthera tenella and Cenchrus echinatus, but showed unsatisfactory control of Senna obtusifolia and Commelina benghalensis, causing significant reductions in crop yield.

Key words: Tank mixture, Roundup Ready ${ }^{\circledR}$ soybean, glyphosate, Glycine max.

\section{Introdução}

A chegada da soja geneticamente modificada, com a característica de tolerância ao glyphosate trouxe aos agricultores mais uma alternativa para o manejo integrado de plantas daninhas (Owen, 2000).

O glyphosate é um herbicida sistêmico de ação total, pertencente ao grupo químico dos inibidores da síntese de aminoácidos, e apresenta o $\mathrm{N}$-(phosphonomethyl) glycina como ingrediente ativo (Bridges, 2003). Em plantas sensíveis, atua inibindo a atividade da enzima plastídica 5-enolpiruvilshiquimato- 3fosfato sintase (EPSPS), responsável pela reação que condensa shiquimato-3-fosfato e fosfoenolpiruvato em 5- enolpiruvilshiquimato3-fosfato (EPSP) e fosfato inorgânico (Pi), na etapa pré-corismato, da rota metabólica do shiquimato. Essa rota é extremamente importante, pois é base para biosintese de aminoácidos aromáticos essenciais como, fenilalanina, tirosina e triptofano (Shaner \& Bridges, 2003).

A tolerância ao herbicida foi obtida pela inserção de um gene (AroA) oriundo do genoma de Agrobacterium sp., estirpe CP4, a qual codifica uma variante da EPSPS (CP4 EPSPS), especialmente tolerante à inibição pelo glyphosate (Padgette et al., 1995). Sob tratamento com esse herbicida, as plantas de soja não são afetadas, devido à ação continuada e sistemática dessa enzima alternativa, insensível ao produto.

Apesar do largo espectro de ação e flexibilidade proporcionada por essa tecnologia, o glyphosate possui limitações com relação ao controle de plantas daninhas mais tolerantes como Richardia brasiliensis, Chamaesyce hirta, Chloris polydacyla, Ipomoea triloba e Ipomoea lacunosa (Norsworthy et al., 2001), Commelina difusa (Santos et al., 2001), Commelina benghalensis (Lacerda \& Victoria Filho, 2004) e Euphorbia heterophylla (Procópio et al., 2007).

$\mathrm{O}$ uso de herbicidas que apresentam diferentes mecanismos de ação, além de aumentar o espectro e/ou melhorar a eficácia de controle, pode prevenir o surgimento de biótipos resistentes. Vários trabalhos já comprovaram a melhor eficácia de tratamentos que associaram glyphosate com outros herbicidas, entre eles o chlorimuron-ethyl e imazethapyr (Vanlieshout \& Loux, 2000; Norsworthy \& Gray, 2004; Procópio et al., 2007). Gonzini, et al. (1999), demonstraram a necessidade de utilizar glyphosate em associação com imazethapyr para que houvesse o controle do Chenopodium album, Setaria faberi e Abutilon theophrasti.

Para alguns autores, essas associações podem acarretar maiores níveis de injúria à cultura. Para Vidrine et al. (2002), intoxicações visuais em soja $R^{\circledR}{ }^{\circledR}$ foram provocadas pela aplicação de misturas de chlorimuron-ethyl com glyphosate, variando de $6 \%$ a pouco mais de 30\%. Ellis \& Griffin (2003), observaram $13 \%$ de intoxicação em plantas de soja $\mathrm{RR}^{\circledR}$ após aplicação de chlorimuron-ethyl com glyphosate $\left(6,7+1.120 \mathrm{~g} \mathrm{ha}^{-1}\right)$. Entretanto, Foloni et al. (2005) observaram leve efeito de intoxicação na cultivar Monsoy $8888 \mathrm{RR}^{\circledR}$, após aplicações isoladas de glyphosate. Franzen et al. (2004), relataram que a fitointoxicação pode ser mais pronunciada 
quando a aplicação do herbicida é seguida de um stress, seja biótico ou abiótico.

São frequentes as indagações a respeito das associações entre misturas em tanque de herbicidas, para o manejo integrado de plantas daninhas na cultura da soja tolerante ao glyphosate. Este trabalho teve por objetivo avaliar a seletividade e a eficácia de misturas em tanque de herbicidas sobre a cultura da soja Roundup Ready ${ }^{\circledR}$.

\section{Material e métodos}

O experimento foi conduzido no município de Rio Verde - GO, localizado a 706 metros de altitude, latitude de $17^{\circ} 53^{\prime} 14,9^{\prime \prime} \mathrm{S}$ e longitude de 5051'28,4" WO. O solo da área experimental é classificado como Latossolo Vermelho distrófico, constituído por $610 \mathrm{~g} \mathrm{~kg}^{-1}$ de Argila, Areia $330 \mathrm{~g} \mathrm{~kg}^{-1}$ e Silte $0,60 \mathrm{~g} \mathrm{~kg}^{-1}$, manejado em sistema de semeadura direta.
A semeadura do cultivar CD $219 \mathrm{RR}^{\circledR}$ foi realizada em 18 de novembro, utilizando se espaçamento de $0,45 \mathrm{~m}$, com população final de 245 mil plantas ha ${ }^{-1}$. As sementes foram tratada com fungicidas Carboxin + Thiram $(114+40 \mathrm{~g}$ para $100 \mathrm{~kg}$ de sementes $) \mathrm{e}$ posteriormente inoculada. $\mathrm{O}$ ensaio foi implantado em área manejada com herbicida glyphosate $\left(1080 \mathrm{~g} \mathrm{ha}^{-1}\right)$, com semeadura aproximadamente dois dias após a aplicação, utilizando-se adubação de base de $380 \mathrm{~kg} \mathrm{ha}^{-1}$ do formulado 02-20-18.

O experimento foi conduzido utilizando-se seis tratamentos e quatro repetições, em delineamento em blocos casualizados. Cada parcela correspondeu a uma área total de $22,05 \mathrm{~m}^{2}$, constituídas por sete linhas de $7 \mathrm{~m}$ de comprimento, com área útil avaliada nas 3 linhas centrais, desprezando-se 1 $m$ nas extremidades. Os tratamentos encontram-se dispostos na Tabela 1.

Tabela 1. Tratamentos herbicidas utilizados no experimento. Rio Verde-GO.

\begin{tabular}{|c|c|c|c|c|}
\hline \multirow{2}{*}{ Nome comum } & \multirow{2}{*}{ Formulação } & Concentração & $\operatorname{Dose}^{1}$ & $\operatorname{Dose}^{2}$ \\
\hline & & g i.a. $L^{-1}$ & gi.a. ha ${ }^{-1}$ & g ou L p.c. ha ${ }^{-1}$ \\
\hline Testemunha capinada & & & & \\
\hline Glyphosate & $\mathrm{CS}$ & 480 & 960 & 2,0 \\
\hline Glyphosate + Agrus $200^{\circledR}$ & $\mathrm{CS}+\mathrm{CS}$ & $480+200$ & $960+0,0012$ & $2,0+0,075$ \\
\hline Glyphosate + chlorimuron-ethyl & $\mathrm{CS}+\mathrm{GRDA}$ & $480+250$ & $960+12,5$ & $2,0+50$ \\
\hline Glyphosate + lactofen & $\mathrm{CS}+\mathrm{CE}$ & $480+240$ & $960+96$ & $2,0+0,400$ \\
\hline Testemunha sem capina & - & - & - & - \\
\hline
\end{tabular}

A aplicação dos tratamentos em pósemergência ocorreu quando a cultura encontravam-se no estádio V4 (terceira folha trifoliolada). Para aplicação, utilizou-se um pulverizador costal pressurizado à $\mathrm{CO}_{2}$, munido de seis pontas de jato plano AI 110.02, espaçadas a $0,5 \mathrm{~m}$, em pressão de trabalho de $40 \mathrm{lb} \mathrm{pol}^{2}$, que proporciou volume de aplicação de $150 \mathrm{~L} \mathrm{ha}^{-1}$.

As aplicações foram realizadas em 12/12/2007 entre 16:00 e 18:30 hs, sendo que as condições climáticas nesse período foram: temperaturas: mínima $28,8^{\circ} \mathrm{C}$, média $29,4{ }^{\circ} \mathrm{C}$ e máxima $30,4^{\circ} \mathrm{C}$; umidade relativa do ar: mínima $72 \%$, média $84 \%$ e máxima $86 \%$ e velocidade do vento: mínima $4 \mathrm{~km} \mathrm{~h}^{-1}$, média $6 \mathrm{~km} \mathrm{~h}^{-1}$ e máxima $8 \mathrm{~km} \mathrm{~h}^{-1}$.

No momento da implantação do experimento na área encontravam se as espécies de plantas daninhas na cultura: apagafogo (Alternanthera tenella) (6 plantas $\mathrm{m}^{2}$; Estádio: 2 a 4 folhas), fedegoso (Senna obtusifolia) (4,5 plantas $\mathrm{m}^{2} ; 2$ folhas), timbete (Cenchrus echinatus) (9,5 plantas $\mathrm{m}^{2}$; Estádio: 2 a 3 folhas) e trapoeraba (Commelina 
benghalensis) (18,5 plantas $\mathrm{m}^{2}$; Estádio: 2 a 4 folhas).

Os níveis de controle das plantas daninhas e fitointoxicação da cultura foram determinados através de notas visuais, onde $0 \%$ representa ausência de controle e $100 \%$ representa controle de todas as plantas, aos 3 , 7, 14 e 21 dias após a aplicação (DAA). Como parâmetros culturais foram avaliados as características altura de plantas e matéria seca aos 21 DAA, assim como a produtividade de grãos, corrigida para $13 \%$ de umidade.

Os resultados foram submetidos à análise de variância, sendo as médias das variáveis comparadas pelo teste de Tukey, a $5 \%$ de probabilidade.

\section{Resultados e Discussão}

A associação entre glyphosate e lactofen proporcionou os mais elevados níveis de fitointoxicação à cultura, durante todas as fases de avaliação (Tabela 2). Aos 3 DAA, este tratamento apresentou $29,8 \%$ de injuria, significativamente superior aos demais. Como sintomas constatou-se inicialmente a presença de manchas com coloração esbranquiçada e aspecto brilhante, nos dois a três dias após a aplicação, evoluindo, em alguns casos, aos 7 DAA, para manchas necróticas nas lâminas foliares, consideradas como sintomas típicos dos herbicidas inibidores da enzima protoporfinogênio oxidase. Resultados semelhantes foram observados por Shaw \& Arnold (2002) em plantas de soja.

Os sintomas foram reduzindo no decorrer das avaliações. Rezende (1995), Foloni et al. (2005) e Oliveira Jr et al. (2006) também observaram que o lactofen foi o herbicida mais fitotóxico à cultura da soja; porém, houve perfeita recuperação dos sintomas visuais, semelhantes aos resultados encontrados no presente ensaio.

Em complemento, para mistura em tanque de glyphosate + lactofen, não foram observados efeitos antagônicos no preparo e utilização da calda de pulverização.

Tabela 2. Fitointoxicação apresentada pelos tratamentos aos 3, 7, 14 e 21 dias após aplicação (DAA), cultivar CD 219 RR, safra 2005/06. Rio Verde- GO.

\begin{tabular}{|c|c|c|c|c|c|c|c|c|}
\hline \multirow{2}{*}{ Tratamentos } & \multirow{2}{*}{ 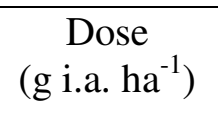 } & \multicolumn{7}{|c|}{ Fitointoxicação (\%) } \\
\hline & & $3 \mathrm{DAA}$ & & $7 \mathrm{DA}$ & & $14 \mathrm{DA}$ & & 21 DAA \\
\hline Testemunha capinada & - & 0,0 & $\mathrm{c}$ & 0,0 & c & 0,0 & c & 0,0 \\
\hline Glyphosate & 960 & 0,0 & $\mathrm{c}$ & 0,0 & c & 0,0 & $\mathrm{c}$ & 0,0 \\
\hline Glyphosate + Agrus $200^{\circledR}$ & $960+0,0012$ & 0,0 & $\mathrm{c}$ & 0,0 & $\mathrm{c}$ & 0,0 & $\mathrm{c}$ & 0,0 \\
\hline Glyphosate + chlorimuron-ethyl & $960+12,5$ & 18,5 & $\mathrm{~b}$ & 13,3 & $\mathrm{~b}$ & 8,3 & b & 0,0 \\
\hline Glyphosate + lactofen & $960+96$ & 29,8 & $\mathrm{a}$ & 25,5 & $\mathrm{a}$ & 20,0 & $\mathrm{a}$ & 8,3 \\
\hline Testemunha sem capina & - & 0,0 & $\mathrm{c}$ & 0,0 & $\mathrm{c}$ & 0,0 & $\mathrm{c}$ & 0,0 \\
\hline
\end{tabular}

DAA = dias após aplicação. Médias de tratamentos não seguidas de mesma letra na coluna diferem entre si pelo teste de Tukey a $5 \%$ de probabilidade.

Ao contrario dos resultados encontrados para glyphoste + lactofen, a mistura glyphosate + chlorimuron-ethyl proporcionou menor nível de injuria $(18,5 \%)$ aos 3 DAA. Entretanto, estes sintomas foram se extinguiram durante as avaliações (Tabela 2). Esses resultados corroboram com os encontrados Procópio et al. (2007). Vidrine et al. (2002) relataram valores para intoxicação visual em plantas de soja $\mathrm{RR}^{\circledR}$, provocados pela aplicação de misturas de chlorimuronethyl com glyphosate, variando de $6 \%$ a pouco mais de 30\%. Ellis \& Griffin (2003), observaram $13 \%$ de intoxicação em plantas de 
soja $\mathrm{RR}^{\circledR}$ após a aplicação de chlorimuronethyl com glyphosate $\left(6,7+1.120 \mathrm{~g} \mathrm{ha}^{-1}\right)$.

Os tratamentos glyphosate de forma isolada, não proporcionaram fitointoxicação à cultura, concordando com os resultados encontrados por Procópio et al. (2007), e discordando de Foloni et al. (2005), onde observaram leve efeito de fitointoxicação em plantas de soja $\mathrm{RR}^{\circledR}$ (cultivar Monsoy 8888 ), após aplicações isoladas de glyphosate.

Outro fato interessante de ser observado é que mesmo a associação do adjuvante Agrus $200^{\circledR}$ ao glyphosate não promoveu sintomas aparentes fitointoxicação na cultivar de soja (Tabela 2). Riechers et al. (1994) relataram que os adjuvantes podem potencializar o efeitos dos herbicidas, com por exemplo, solubilizando o complexo de ceras existentes na superfície foliar, a ponto de reduzir a seletividade, fato esse não observado no presente ensaio. Segundo Norsworthy \& Grey (2004), a adições de surfatantes não iônicos aumentou a toxicidade à soja resistente ao glyphosate. Carvalho (2000) afirmou que nem sempre misturas de glyphosate com adjuvante resultam em efeitos sinérgicos, e em alguns casos pode-se ocorrer antagonismo.

Com relação ao controle das plantas daninhas (tabela 3), observa se que a mistura glyphosate + lactofen proporcionou $53,3 \%$ de controle da Alternanthera tenella aos 3 DAA, diferindo dos demais tratamentos herbicidas e da testemunha. Esse fato se deve a presença do lactofen.

Tabela 3. Controle de Alternanthera tenella, aos 3, 7, 14 e 21 dias após aplicação dos herbicidas na cultura da soja, cultivar CD 219 RR, safra 05/2006. Rio Verde- GO.

\begin{tabular}{|c|c|c|c|c|c|c|c|c|c|}
\hline \multirow{2}{*}{ Tratamentos } & \multirow{2}{*}{$\begin{array}{c}\text { Dose } \\
\left(\mathrm{g} \text { i.a. } \mathrm{ha}^{-1}\right)\end{array}$} & \multicolumn{8}{|c|}{ Controle $(\%)$} \\
\hline & & $3 \mathrm{DA}$ & & $7 \mathrm{DAA}$ & & 14 DAA & & 21 DAA & \\
\hline Testemunha capinada & - & 100,0 & $\mathrm{a}$ & 100,0 & $\mathrm{a}$ & 100,0 & $\mathrm{a}$ & 100,0 & $\mathrm{a}$ \\
\hline Glyphosate & 960 & 34,5 & $\mathrm{~cd}$ & 83,8 & $\mathrm{~b}$ & 93,8 & $\mathrm{a}$ & 100,0 & $\mathrm{a}$ \\
\hline Glyphosate + Agrus $200^{\circledR}$ & $960+0,0012$ & 37,5 & $\mathrm{c}$ & 90,0 & $\mathrm{~b}$ & 100,0 & a & 100,0 & a \\
\hline Glyphosate + chlorimuron-ethyl & $960+12,5$ & 32,5 & $\mathrm{~d}$ & 88,8 & b & 100,0 & $\mathrm{a}$ & 100,0 & a \\
\hline Glyphosate + lactofen & $960+96$ & 53,3 & $\mathrm{~b}$ & 90,0 & $\mathrm{~b}$ & 100,0 & $\mathrm{a}$ & 100,0 & $\mathrm{a}$ \\
\hline Testemunha sem capina & - & 0,0 & $\mathrm{e}$ & 0,0 & $\mathrm{c}$ & 0,0 & $\mathrm{~b}$ & 0,0 & $\mathrm{~b}$ \\
\hline
\end{tabular}

DAA = dias após aplicação. Médias de tratamentos não seguidas de mesma letra na coluna diferem entre si pelo teste de Tukey a $5 \%$ de probabilidade.

Apesar dos baixos níveis de controle aos 3 DAA, todos os herbicidas apresentaram controle superior a $83 \%$ a partir dos 7 DAA, e acima de $93 \%$ nas demais avaliações, não diferindo entre si. Estes resultados demonstram que a adição dos herbicidas chlorimuron-ethyl e lactofen, e/ou mesmo do adjuvante Agrus $200^{\circledR}$, em mistura em tanque ao glyphosate, não trouxe incrementos significativos para o controle dessa espécie.

No que se refere ao controle do Cenchrus echinatus (Tabela 4), todos os tratamentos apresentaram controle abaixo dos níveis adequados aos 3 DAA. Entretanto, os tratamentos glyphosate + Agrus $200^{\circledR} \mathrm{e}$ glyphosate + chlorimuron-ethyl diferiram dos demais tratamentos com 52 e $50 \%$ de controle, respectivamente, durante esse período inicial.

Glyphosate + Agrus $200^{\circledR}$, glyphosate + chlorimuron-ethyl e glyphosate + lactofen aos 14 DAA (Tabela 4), obtiveram 97, 100 e 100 $\%$ de controle de C. echinatus, respectivamente, diferindo significativamente do glyphosate aplicado isolado (75\%).

Apesar das diferenças inicialmente observadas, todos os tratamentos 
proporcionaram controle pleno dessa espécie os resultados encontrados por Barros et al. aos 21 DAA, não diferindo da testemunha (2000), ao mostrar a sensibilidade do $C$. capinada. Estas observações corroboram com echinatus ao herbicida glyphosate.

Tabela 4. Controle de Cenchrus echinatus, aos 3, 7, 14 e 21 dias após aplicação dos herbicidas na cultura da soja, cultivar CD 219 RR, safra 05/2006. Rio Verde- GO.

\begin{tabular}{lcrrrrrrr}
\hline \multirow{2}{*}{ Tratamentos } & \multirow{2}{*}{\begin{tabular}{c} 
Dose \\
\cline { 3 - 8 }
\end{tabular}} & $\left({\left.\mathrm{g} \mathrm{i} \text { i. } \mathrm{ha}^{-1}\right)}^{n}\right.$ & 3 DAA & 7 DAA & 14 DAA & 21 DAA \\
\hline Testemunha capinada & - & $100,0 \mathrm{a}$ & 100,0 & $\mathrm{a}$ & 100,0 & $\mathrm{a}$ & 100,0 & $\mathrm{a}$ \\
Glyphosate & 960 & $40,5 \mathrm{~d}$ & 58,8 & $\mathrm{~b}$ & 75,0 & $\mathrm{~b}$ & 100,0 & $\mathrm{a}$ \\
Glyphosate + Agrus 200 & $960+0,0012$ & $52,3 \mathrm{~b}$ & 72,5 & $\mathrm{~b}$ & 97,5 & $\mathrm{a}$ & 100,0 & $\mathrm{a}$ \\
Glyphosate + chlorimuron-ethyl & $960+12,5$ & $50,0 \mathrm{bc}$ & 71,3 & $\mathrm{~b}$ & 100,0 & $\mathrm{a}$ & 100,0 & $\mathrm{a}$ \\
Glyphosate + lactofen & $960+96$ & $42,5 \mathrm{~cd}$ & 66,5 & $\mathrm{~b}$ & 100,0 & $\mathrm{a}$ & 100,0 & $\mathrm{a}$ \\
Testemunha sem capina & - & $0,0 \mathrm{e}$ & 0,0 & $\mathrm{c}$ & 0,0 & $\mathrm{c}$ & 0,0 & $\mathrm{~b}$ \\
\hline
\end{tabular}

DAA = dias após aplicação. Médias de tratamentos não seguidas de mesma letra na coluna diferem entre si pelo teste de Tukey a $5 \%$ de probabilidade.

Para o controle do fedegoso (Tabela 5), em nenhuma das datas de avaliação, os tratamentos utilizados não apresentaram eficácia, todavia os maiores níveis de controle foram alcançados nas associações entre glyphosate + chlorimuron-ethyl e glyphosate + lactofen ao proporcionar, respectivamente, níveis de controle de 32 e 45,8\%, aos 7 DAA e 46,3 e $33,3 \%$, aos 21 DAA, os quais são considerados muito abaixo dos patamares aceitáveis. Estes resultados demonstram a ineficiência dos tratamentos estudados em relação ao controle de $S$. obtusifolia, sendo importante salientar que essa espécie é muito frequente na região dos cerrado, e que alternativas de controle deve ser tomada com relação à mesma.

Tabela 5. Controle de Senna obtusifolia, aos 3, 7, 14 e 21 dias após aplicação dos herbicidas na cultura da soja, cultivar CD 219 RR, safra 05/2006. Rio Verde, GO.

\begin{tabular}{|c|c|c|c|c|c|c|c|c|c|}
\hline \multirow{2}{*}{ Tratamentos } & \multirow{2}{*}{ 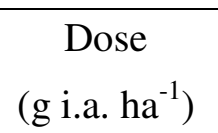 } & \multicolumn{8}{|c|}{ Controle (\%) } \\
\hline & & $3 \mathrm{DAA}$ & & 7 DAA & & $14 \mathrm{DAA}$ & & $21 \mathrm{DAA}$ & \\
\hline Testemunha capinada & - & 100,0 & $\mathrm{a}$ & 100,0 & $a$ & 100,0 & $\mathrm{a}$ & 100,0 & $\mathrm{a}$ \\
\hline Glyphosate & 960 & 16,8 & $\mathrm{c}$ & 15,5 & $\mathrm{~d}$ & 10,8 & $\mathrm{c}$ & 3,8 & $\mathrm{~d}$ \\
\hline Glyphosate + Agrus $200^{\circledR}$ & $960+0,0012$ & 21,0 & $\mathrm{c}$ & 17,0 & $\mathrm{~d}$ & 13,3 & $\mathrm{c}$ & 4,5 & $\mathrm{~d}$ \\
\hline Glyphosate + chlorimuron-ethyl & $960+12,5$ & 17,0 & $\mathrm{c}$ & 32,0 & $\mathrm{c}$ & 40,8 & $\mathrm{~b}$ & 46,3 & $\mathrm{~b}$ \\
\hline Glyphosate + lactofen & $960+96$ & 36,5 & $\mathrm{~b}$ & 45,8 & $\mathrm{~b}$ & 41,3 & b & 33,3 & $\mathrm{c}$ \\
\hline Testemunha sem capina & - & 0,0 & d & 0,0 & $\mathrm{e}$ & 0,0 & $\mathrm{~d}$ & 0,0 & $\mathrm{~d}$ \\
\hline
\end{tabular}

$\overline{\mathrm{DAA}}=$ dias após aplicação. Médias de tratamentos não seguidas de mesma letra na coluna diferem entre si pelo teste de Tukey, a 5\% de probabilidade.

Assim como para S. obtusifolia, espécie (41,35 \%), diferindo dos demais semelhantes resultados de ineficiência de tratamentos, que também apresentaram ainda controle foram obtidos para Commelina mais inferiores aos níveis de controle benghalensis (Tabela 6). Aos 14 DAA, aceitáveis. Resultados semelhantes foram somente o tratamento glyphosate + lactofen obtidos aos 21 DAA, sendo totalmente obteve os melhores níveis de eficácia dessa 
ineficientes os tratamentos com glyphosate e glyphosate + Agrus $200^{\circledR}$.

Estes resultados corroboram com os encontrados por Nishikawa et al. (2007), ao avaliar o desempenho $480 \mathrm{~g} \mathrm{ha}^{-1}$ de glyphosate no controle dessa espécie. Lacerda \& Victoria Filho (2004), observaram que dentre as espécies estudadas, a $C$. benghalensis

Tabela 6. Controle da Commelina benghalensis, em percentagens, aos 3, 7, 14 e 21 dias após aplicação dos herbicidas. Safra 05/06. Rio Verde, GO.

\begin{tabular}{|c|c|c|c|c|c|c|c|c|c|}
\hline \multirow{2}{*}{ Tratamentos } & \multirow{2}{*}{$\begin{array}{c}\text { Dose } \\
\left(\mathrm{g} \text { i.a. } \mathrm{ha}^{-1}\right)\end{array}$} & \multicolumn{8}{|c|}{ Controle $(\%)$} \\
\hline & & $3 \mathrm{DAA}$ & & 7 DAA & & 14 DAA & & $21 \mathrm{DAA}$ & \\
\hline Testemunha capinada & - & 100,0 & $\mathrm{a}$ & 100,0 & $\mathrm{a}$ & 100,0 & $\mathrm{a}$ & 100,0 & $\overline{\mathrm{a}}$ \\
\hline Glyphosate & 960 & 9,0 & $\mathrm{~d}$ & 5,5 & $\mathrm{~d}$ & 0,0 & $\mathrm{~d}$ & 0,0 & $\mathrm{c}$ \\
\hline Glyphosate + Agrus $200^{\circledR}$ & $960+0,0012$ & 17,5 & $\mathrm{c}$ & 10,8 & $\mathrm{~d}$ & 5,8 & $\mathrm{~d}$ & 0,0 & $\mathrm{c}$ \\
\hline Glyphosate + chlorimuron-ethyl & $960+12,5$ & 17,5 & $\mathrm{c}$ & 21,8 & $\mathrm{c}$ & 30,0 & $\mathrm{c}$ & 30,8 & $\mathrm{~b}$ \\
\hline Glyphosate + lactofen & $960+96$ & 33,8 & $\mathrm{~b}$ & 40,3 & $b$ & 41,8 & $\mathrm{~b}$ & 33,8 & $\mathrm{~b}$ \\
\hline Testemunha sem capina & - & 0,0 & $\mathrm{e}$ & 0,0 & $\mathrm{e}$ & 0,0 & $\mathrm{~d}$ & 0,0 & $\mathrm{c}$ \\
\hline
\end{tabular}

DAA = dias após aplicação. Médias de tratamentos não seguidas de mesma letra na coluna diferem entre si pelo teste de Tukey, a $5 \%$ de probabilidade.

Verifica-se que na Tabela 7 os tratamentos glyphosate + chlorimuron-ethyl e glyphosate + lactofen apresentaram significativa redução na característica altura de plantas aos 21 DAA, inferior aos resultados obtidos pela testemunha capinada. Esse fato pode estar relacionado tanto pela presença de plantas daninhas em função das falhas no controle, quanto em pela seletividade das misturas. Para Foloni et al. (2005), uso dos herbicidas glyphosate e chlorimuron-ethyl na cultura de soja transgênica M Soy 8888 RR, tanto em pós-emergência em aplicações única ou sequenciais de glyphosate, influenciou na altura das plantas da cultura até 15 DAA, a qual recuperou-se após esse período. No entanto, Barros et al. (2000), não constataram diferenças significativas na característica altura de planta para os tratamentos com misturas em tanque dos herbicidas, chlorimuron-ethyl + apresentou maior tolerância ao glyphosate, necessitando de dose superior a $1.440 \mathrm{~g} \mathrm{ha}^{-1}$ para que se tenha redução $50 \%$ de sua matéria seca. Procópio et al. (2007) necessitou de 1440 +10 e $1440+50 \mathrm{~g} \mathrm{ha}^{-1}$ de glyphosate + chlorimuron-ethyl e glyphosate + imazethapyr, respectivamente, para controlar 88 e $85 \%$ da C. benghalensis, aos 25 DAA. lactofen e chlorimuron-ethyl + imazethapyr, em relação à testemunha capinada.

Embora a variável altura de plantas tenha sofrido alterações em função dos tratamentos (Tabela 7), não foram constatadas diferenças significativamente no acumulo de matéria seca, aos 21 DAA.

A ausência de controle das plantas invasoras reduziu significativamente $(58 \%)$ a produtividade da cultura, justificando a necessidade de controle das plantas daninhas. Todavia, todos os tratamentos, com exceção do glyphosate + Agrus $200^{\circledR}$, diferiram significativamente da testemunha capinada, que apresentou produtividade média de 3000 $\mathrm{kg} \mathrm{ha}^{-1}$. Esta redução da produtividade pode estar estritamente relacionada com os baixos níveis de controle da $C$. benghalensis, espécie com maior frequência $\left(18,5\right.$ plantas $\left.\mathrm{m}^{2}\right)$ no momento da aplicação. 
Tabela 7. Altura da planta, acúmulo de matéria seca e produtividade da cultivar CD $219 \mathrm{RR}^{\circledR}$, safra 05/2006. Rio Verde, GO.

\begin{tabular}{|c|c|c|c|c|}
\hline Tratamentos & $\begin{array}{c}\text { Dose } \\
\left(\text { g i.a. } \text { ha }^{-1}\right)\end{array}$ & $\begin{array}{l}\text { Altura } \\
(\mathrm{cm})\end{array}$ & $\begin{array}{c}\text { Massa seca } \\
(\%)\end{array}$ & $\begin{array}{l}\text { Produtividade } \\
\qquad\left(\mathrm{kg} \mathrm{ha}^{-1}\right)\end{array}$ \\
\hline Testemunha capinada & - & $51,0 \mathrm{a}$ & $48,0 \quad \mathrm{a}$ & 3000 \\
\hline Glyphosate & 960 & $45,0 \mathrm{ab}$ & 52,5 a & 2610 \\
\hline Glyphosate + Agrus $200^{\circledR}$ & $960+0,0012$ & $45,2 \mathrm{ab}$ & 52,0 a & 2730 \\
\hline Glyphosate + chlorimuron-ethyl & $960+12,5$ & $44,1 \mathrm{~b}$ & $48,0 \quad \mathrm{a}$ & 2580 \\
\hline Glyphosate + lactofen & $960+96$ & $43,0 \mathrm{~b}$ & $46,0 \quad a$ & 2610 \\
\hline Testemunha sem capina & - & $46,0 \mathrm{ab}$ & 55,0 a & 1365 \\
\hline
\end{tabular}

Médias de tratamentos não seguidas de mesma letra na coluna diferem entre si pelo teste de Tukey a 5\% de probabilidade.

\section{Conclusões}

Todos os tratamentos foram eficientes no controle Alternanthera tenella e Cenchrus echinatus, e insatisfatórios da Senna obtusifolia e Commelina benghalensis.

A presença de plantas daninhas influenciou negativamente na produtividade da soja CD $219 \mathrm{RR}^{\circledR}$, justificando o seu controle.

\section{Referências}

BRIDGES, D.C. Glyphosate-type herbicidas. In: BRIDGES, D.C. Herbicide action course. West Lafayette: Purdue University, 2003. p.501-513.

BARROS, A.C. et al. Eficiência e seletividade do lactofen em mistura com outros latifolicidas, no controle de plantas daninhas na cultura da soja. Revista Brasileira de Herbicidas, v.1, n.1, p.79-84, 2000.

CARVALHO, F.T. et al. Eficácia de herbicidas no manejo de Euphorbia heterophylla para o plantio direto de soja. Revista Brasileira de Herbicidas, v.1, n.2, p.159-165, 2000.

ELLIS, J.M.; GRIFFIN, J.L. Glyphosate and broadleaf herbicide mixtures for soybean (Glycine max). Weed Technology, v.17, n.3, p.21-27, 2003.
FOLONI, L.L. et al. Aplicação de glyphosate em pós-emergência, em soja transgênica cultivada no cerrado. Revista Brasileira de Herbicidas, v.5, n.3, p.47-58, 2005.

FRANZEN, D. et al. Influence of certain postemergence broadleaf herbicides on soybean stressed from iron deficiency chlorosis. Agronomy Journal, v.96, n.2, p.1357-1363, 2004.

GONZINI, M. et al. Herbicide combinations for weed management in glyphosate-resistant soybean (Glycine max). Weed Technology, v,13, n.3, p.354-360, 1999.

LACERDA, A.L.S.; VICTORIA FILHO, R. Curvas dose-resposta em espécies de plantas daninhas com o uso do herbicida glyphosate.

Bragantia, v.63, n.1, p.73-79, 2004.

NISHIKAWA, M.A.N et al. Estudo comparativo do sistema Roundup Ready com herbicidas convencionais de pósemergência no controle de plantas daninhas na cultura da soja geneticamente modificada Roundup Ready (Evento GTS40-3-2). Disponível em: <http://www.monsanto.com.br/ biotecnologia/estudos/estudos/pdf/xxivcongres so/357.pdf>. Acesso em: 24/07/2007.

NORSWORTHY, J.K. et al. Differences in weed tolerance to glyphosate involve different 
mechanisms. Weed Technology, v.15, n.4, p.725-731, 2001.

NORSWORTHY, J.K., GREY, T.L. Addition of nonionic surfactant to glyphosate plus chlorimuron. Weed Technology, v.18, n.3, p.588-593, 2004.

REZENDE, A.M. Eficácia e seletividade dos herbicidas imazethapyr e flumioxazin, na cultura da soja (Glycine max (L.) Merril). 1995. 105f. Tese (Doutorado em Produção Vegetal) - FCAV/Universidade Estadual Paulista, Jaboticabal, 1995.

SHAW, D.R.; ARNOLD, J.C. Weed control from herbicide combinations with glyphosate. Weed Technology, v.16, n.3, p.1-6, 2002.

SANTOS, I.C. et al. Eficiência do herbicida glyphosate no controle de Commelina benghalensis e Commelina diffusa. Planta Daninha, v.19, n.1, p.135-143, 2001.

VANLIESHOUT, L.A.; LOUX, M.M. Interactions of glyphosate with residual herbicides in no-till soybean (Glycine max) production. Weed Technology, v.14, n.2, p.480- 487, 2000.

VIDRINE, P.R. et al. Evaluation of reduced rates of glyphosate and chlorimuron in glyphosate-resistant soybean (Glycine max). Weed Technology, v.16, n.4, p.731-736, 2002.

OLIVEIRA JR., R.S. et al. Aplicações sequenciais de flumiclorac-pentil pentil para o controle de Euphorbia heterophylla na cultura da soja. Acta Scientiarum Agronomy, v.28, n.1, p.115 -122, 2006.

OWEN, M.D.K. Current use of transgenic herbicide-resistant soybean and corn in the USA. Crop Protection, v,19, n.1, p.8-10, 2000.

PROCÓPIO, S.O. et al. Utilização de chlorimuron-ethyl e imazethapyr na cultura da soja Roundup Ready. Planta Daninha, v.25, n.2, p.365-373, 2007.
PADGETTE, S.R. et al. New weed control opportunities: Development of glyphosatetolerant soybeans. In: DUKE, S. O. (Ed.) Herbicide resistant crops. p.54-80. 1995.

RIECHERS, D.E. et al. Surfactant-increased glyphosate uptake into plasma membrane vesicles isolated from common lambsquarters leaves. Plant Physiology, v.105, n.3, p.14191425, 1994.

SHANER, D.; BRIDGES, D. Inhibitors of aromatic amino acid biosyntesis (glyphosate). In: SHANER, D.; BRIDGES, D. Herbicide action course. West Lafayette: Purdue University, 2003. p. 514-529. 